\title{
Antimicrobial resistance in Canada: Update on activities of the Canadian Committee on Antibiotic Resistance
}

\author{
John Conly MD FRCPC, for the Canadian Committee on Antibiotic Resistance
}

\section{NATIONAL POLICY CONFERENCE}

The Canadian Committee on Antibiotic Resistance (CCAR) hosted a National Policy Conference from October 5 to 7, 2002 in Aylmer, Quebec. The goal of the meeting was to gain input on the ongoing development of a National Action Plan to address problems related to antibiotic resistance. The invitational conference gathered 125 experts from the health, agriculture and aquaculture sectors, including healthcare professionals and representatives of government, academia, nonprofit organizations and industry.

The event built upon groundwork for a national strategy initiated by Health Canada in 1997. The policy conference was designed to revisit and test the continued validity of key recommendations emanating from the 1997 efforts, to mark milestones achieved in the control of resistance, to identify areas of consensus and debate among experts, and to set priorities for the next phase in the development of an integrated Canadian action plan. The meeting employed a consensusbuilding process that generated discussion reports and recommendations on a range of topics.

Five themes emerged as clear priorities for national action:

- Implementing an integrated surveillance system dealing with antimicrobial resistance for both human and animal pathogens

- Optimizing antibiotic use in both human and animal settings

- Improving infection prevention methods

- Identifying research priorities

- Consolidating and extending education efforts through a multidisciplinary information program

Financial and policy considerations were explored as components of the above themes. CCAR will use information compiled from the conference to further the formulation of the National Action Plan. For more information or copies of the conference summary, contact Rick Walter atccar@shaw.ca.

\section{PHARMACIST INFORMATION KIT}

Also in October 2002, CCAR and the Canadian Pharmacists Association distributed a Pharmacists' Antibiotic Kit to more than 22,000 practising pharmacists in Canada. The kit con- tains educational resources from the Alberta "Do Bugs Need Drugs?" program, listings of Web sites for public and professional information on antibiotic resistance, recommendations for proper disposal of outdated medications, and suggestions for addressing the overuse of antibiotics with patients and prescribers. An evaluation of the kit will be conducted in the spring of 2003. The program was funded by an unrestricted educational grant from Aventis Pharma Inc. For information, contact Barry Power, bpower@pharmacists.ca.

\section{EDUCATIONAL EFFORTS}

CCAR is working with industry and organizational partners to build financial support for educational efforts related to antibiotic resistance. Several programs have been developed in Canada to raise public and professional awareness of resistance issues and to reduce the inappropriate use of antimicrobial agents. Examples of educational initiatives include "Do Bugs Need Drugs?", in its third year in the Edmonton Capital Health Region, and the Ontario-based Partners for Appropriate Antibiotic Community Therapy (PAACT). The Alberta program, with government and industry sponsorship, continues to expand. The program introduced a daycare information program in 2002 and plans to pilot a seniors' project early this year. For information, contact Edith Blondel-Hill, eblondel@cha.ab.ca; Web site <www.dobugsneeddrugs.org>. PAACT is an independent professional education program developed and operated by family physicians. While the program has received international recognition and has demonstrated cost benefit and positive change in prescriber antibiotic use and selection, PAACT is currently unable to meet the demand for training sessions due to lack of core funding. For information, contact paact@mumshealth.com.

Following is a summary of activities of selected CCARaffiliated organizations and individuals.

\section{CANADIAN INTEGRATED PROGRAM FOR} ANTIMICROBIAL RESISTANCE SURVEILLANCE Health Canada has been working for several years with federal, provincial and university partners to develop a nationally integrated antimicrobial resistance surveillance program. These efforts resulted in the formation of the Canadian Integrated Program for Antimicrobial Resistance Surveillance (CIPARS) 
during the summer of 2002. CIPARS has begun several pilot projects in both the human and veterinary sectors, collecting information on antimicrobial use and antimicrobial resistance in enteric pathogens and commensal organisms from the agrifood sectors (farm level, abattoir level and retail level) and in enteric organisms isolated from humans. These pilot projects have been developed to test the feasibility of a representative, methodologically unified approach, modeled after international initiatives such as the National Antimicrobial Resistance Monitoring System (NARMS, United States) and the Danish Integrated Antimicrobial Resistance Monitoring and Research Programme (DANMAP, Denmark), to monitor trends in the development of antimicrobial resistance in pathogens from humans, animals and food sources.

CIPARS recently launched the national abattoir antimicrobial resistance surveillance pilot project. Samples are being collected from a representative population of healthy chickens, cattle and swine in 50 randomly selected, federally registered abattoirs across Canada. Targeted research projects, including farm level and retail level studies, support the active surveillance initiatives. A collaborative project coordinated by Health Canada began in the fall of 2002, involving participation by all provincial public health laboratories. Salmonella isolates recovered from human cases will be forwarded to Health Canada for antimicrobial resistance testing, and human resistance data will be integrated with agri-food data and antimicrobial usage information to examine antimicrobial resistance along the food chain. Work continues on the development of systems for monitoring antimicrobial use in agriculture and veterinary medicine, and in the treatment of human enteric illness. Additional studies are being conducted to increase knowledge of the links between the use of antimicrobials and the development of resistance in commensals and pathogens. For more information on CIPARS or on specific project activities, contact Health Canada: Laboratory for Foodborne Zoonoses (agri-food issues), Rebecca Irwin, rebecca_irwin@hcsc.gc.ca; Centre for Infectious Disease Prevention \& Control (human enteric issues), Kathryn Doré, kathryn_dore@hcsc.gc.ca; National Laboratory for Enteric Pathogens, Rafiq Ahmed, rafiq_ahmed@hc-sc.gc.ca.

\section{CALGARY REGIONAL ANTIBIOTIC-RESISTANT ORGANISMS PROGRAM AND RESEARCH FUND}

The Calgary Health Region (CHR), in conjunction with Calgary Laboratory Services (CLS), has established a regional program specifically funded to prevent and control the spread of antibiotic-resistant organisms (AROs) within all sectors of a health region comprising 1.2 million people. The program focuses both on providing the clinical microbiology laboratory services necessary to detect resistant microorganisms and on preventing the indiscriminate use of antimicrobial agents. CLS was formed in 1996 as a public-private partnership between MDS-Kasper and the CHR to provide integrated regional laboratory services to Calgary and several adjacent rural healthcare regions, consolidating all antibiotic susceptibility test results, molecular epidemiology results and ARO isolates in a central location. The program includes infectious diseases physicians, pharmacists, infection prevention and control practitioners, data analysts, and a dedicated molecular microbiology laboratory. The creation of a regional program directed against AROs, one of the first of its kind in Canada, may provide a model for other regionalized health service jurisdictions. In addition, a partnership was established between CLS, CHR, Calgary Health Trust (CHT) and the University of Calgary to create the ARO Research Fund within the CHT, providing financial support for ARO research activities. Over $\$ 850,000$ has been raised from donations from private corporations, grants and in-kind contributions from CLS. For information, contact John Conly, john.conly@calgaryhealthregion.ca or Deirdre Church, Deirdre.Church@CLS.ab.ca.

\section{UNIVERSITY OF CALGARY/AGRICULTURE CANADA CATTLE STUDY}

The University of Calgary and Agriculture Canada are collaborating on a study, "Antibiotic Resistance in Cattle and Potential Transmission to Humans," to evaluate the level of antibiotic resistance in marker organisms in feedlot cattle raised using standard production techniques. Funded by the CanadaAlberta Beef Industry Development Fund, the project involves testing the animals as well as feedlot employees for the carriage of antibiotic-resistant strains of potential pathogens. Results of formal susceptibility testing of recovered organisms will be correlated with clinical data on the animals, including feeding protocols, antibiotic treatment during the growth period, and feed supplements. An experimental study of cattle is being performed simultaneously at the Agriculture Canada research facility in Lethbridge, Alberta in which animals are fed specific antibiotics under controlled conditions, and are then sampled to observe the effect on nasal and fecal flora. Results will provide a baseline for monitoring changes in antibiotic resistance profiles in flora carried by cattle. For information, contact Ron Read, ron.read@crha-health.ab.ca.

\section{VANCOUVER ISLAND EPIDEMIOLOGY PROGRAM}

Vancouver Island Health Authority and Nanaimo Regional General Hospital have established a program that provides a useful model for addressing AROs through a collaborative community and hospital epidemiology program. The program uses a multidisciplinary approach to unite various activities, including a home intravenous program, pharmacy monitoring of antibiotic utilitization, infection control, clinical microbiology and the establishment of an outpatient infectious diseases clinic to serve central and north Vancouver Island. Data are available demonstrating improved patient outcome, control of resistant organisms and cost benefits. For information, contact Yaz Mirzanejad, Yazdan.Mirzanejad@cvihr.bc.ca.

\section{CANADIAN PUBLIC HEALTH ASSOCIATION}

The Canadian Public Health Association (CPHA) represents a diverse range of public and community health professionals throughout Canada. In most Canadian jurisdictions, AROs are not notifiable under public health acts governing communicable diseases. As a result, public health response to resistance 
issues is not standardized nationally. However, CPHA encourages collaboration and communication among individuals, institutions and public health networks as the basis for effective interventions. Various public health organizations and professionals are involved in efforts to reduce problems caused by inappropriate antibiotic prescribing, and in education on handwashing and basic hygiene as infection control measures. CPHA has taken an active stance in attempting to limit the use of antimicrobial agents in personal and home cleaning products. CPHA, a member of CCAR, is also a partner in the National Information Program on Antibiotics, a coalition of professional health organizations supported by an educational grant from Pfizer Canada Inc, which provides information and resources to promote the appropriate use of antibiotics. For information, contact Janet MacLachlan, jmaclachlan@cpha.ca, Web site <www.cpha.ca>.

\section{ONTARIO MINISTRY OF HEALTH}

The Ontario Ministry of Health and Long-Term Care has agreed to provide a limited amount of funding to each of the province's 37 health units to support educational initiatives related to antimicrobial resistance. Other Ministry activities include the distribution to each health unit of current antiinfective guidelines for community-acquired infections, and the facilitation of an educational workshop on resistance issues for regional medical officers of health and health unit staff. For information, contact Anne-Luise Winter, anne-luise.winter@moh.gov.on.ca.

\section{MANITOBA ANTIBIOTIC RESISTANCE LABORATORY}

The Manitoba Antibiotic Resistance Laboratory (MARL) has begun new population modeling and analysis studies to assess target attainment of antibiotics against resistant organisms both in healthy volunteers and in patients with infectious diseases. These analyses can be used to predict bacteriological eradication and in the prevention of resistance. MARL is a hospital and university sponsored research group of the Health Sciences Centre (Winnipeg) and the University of Manitoba. For information, contact George Zhanel, ggzhanel@pcs.mb.ca.

CCAR was formed in 1997 to coordinate efforts to control the development and transmission of antibiotic resistance in Canada. CCAR's activities are funded primarily through a contract agreement with Health Canada as well as through educational grants from companies with an interest in antibiotic resistance. Members include health care professional organizations, not-for-profit industrial associations and government agencies. CCAR receives administrative support from the Canadian Infectious Disease Society.

For more information about CCAR, please contact Rick Walter, Executive Director, Canadian Committee on Antibiotic Resistance, 3806 West 33rd Avenue, Vancouver, British Columbia V6N 2H6. Telephone 604-263-4520, fax 604-263-7074, e-mail ccar@shaw.ca, Web site <www.ccar-ccra.org>. 


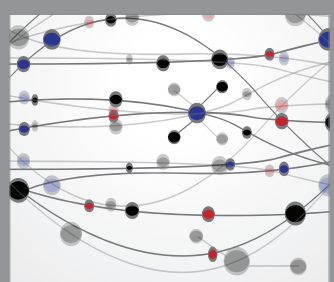

The Scientific World Journal
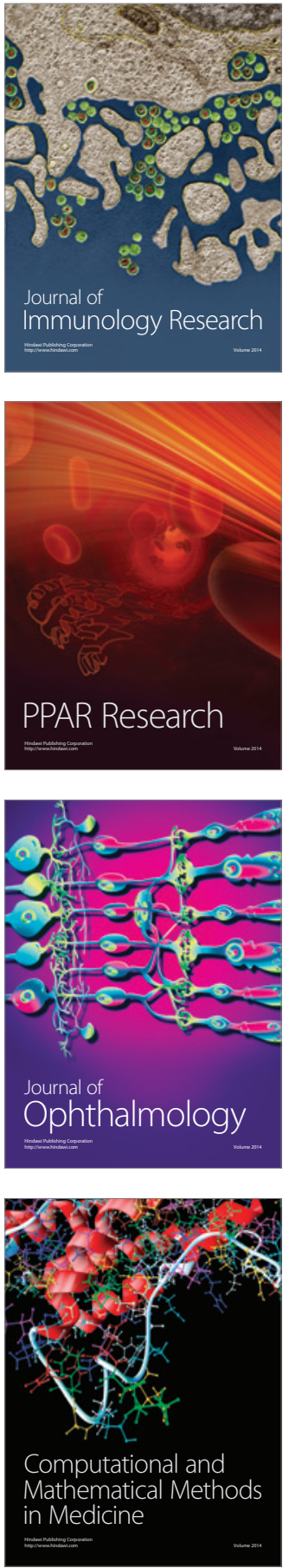

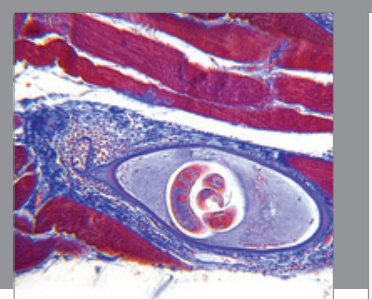

Gastroenterology Research and Practice

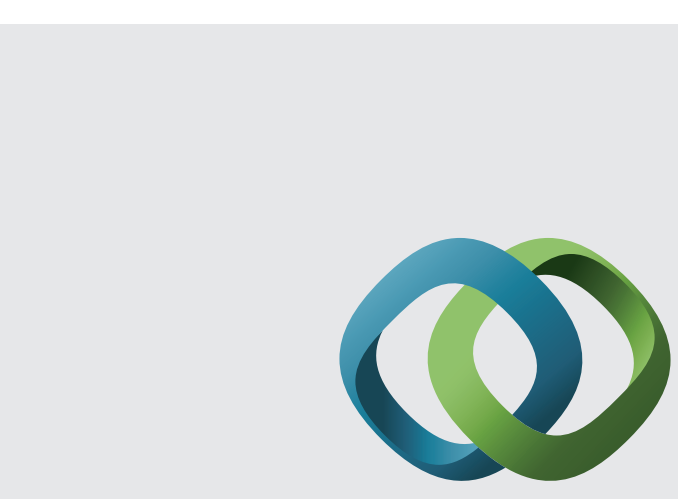

\section{Hindawi}

Submit your manuscripts at

http://www.hindawi.com
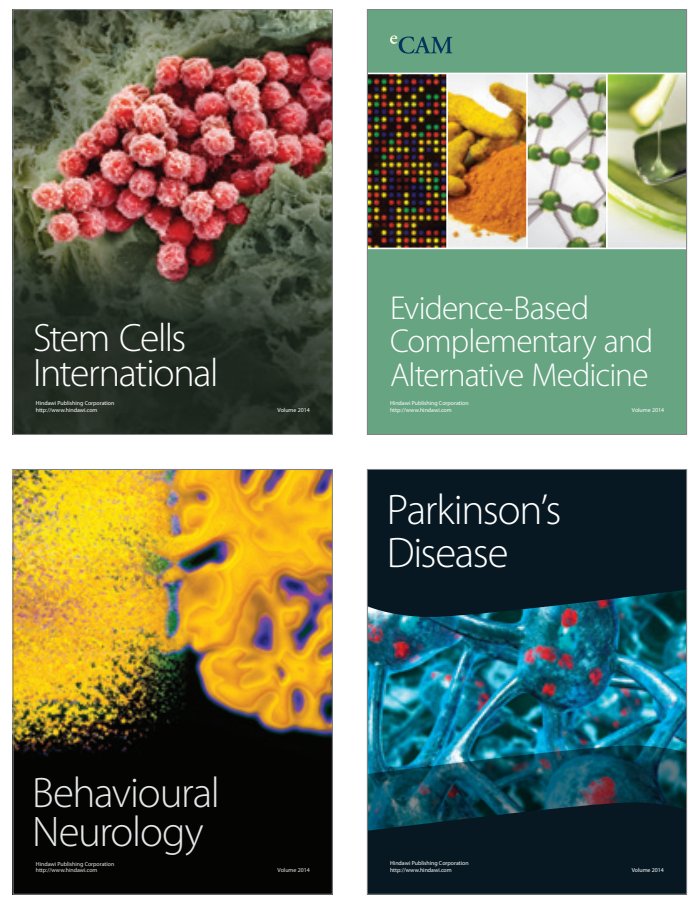
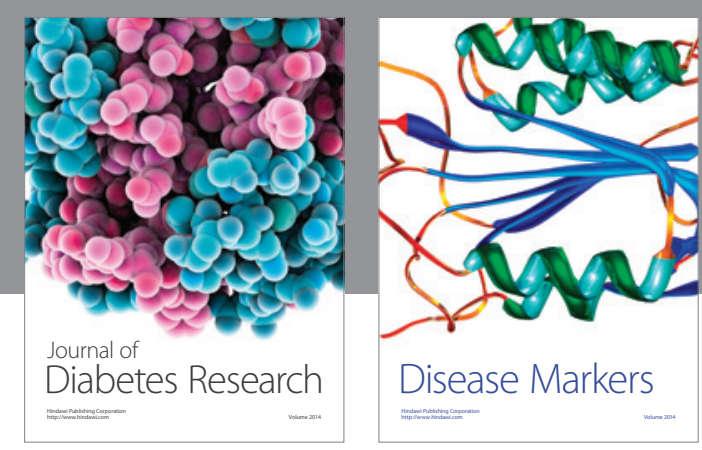

Disease Markers
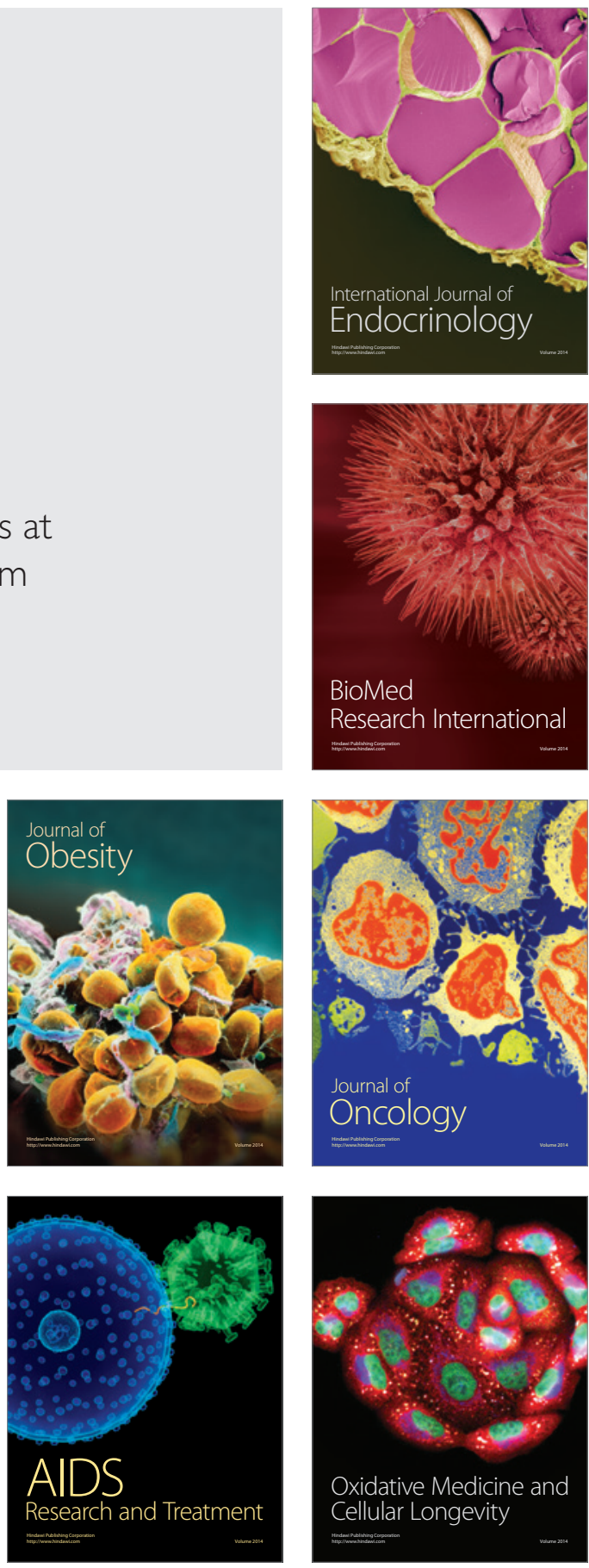